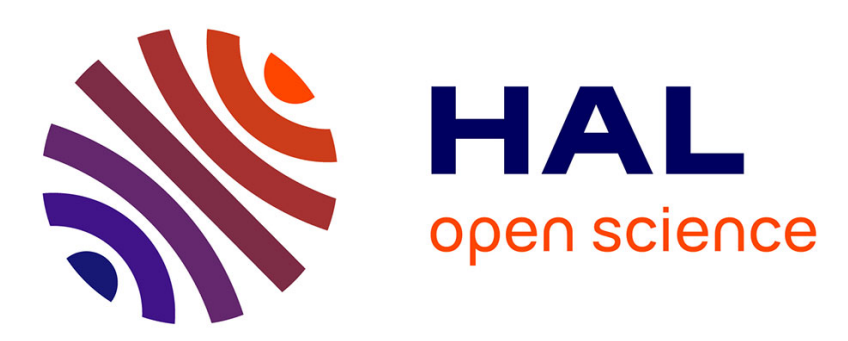

\title{
The deformation and recrystallization behaviour of an Mg-Dy alloy processed by plane strain compression
}

Fairouze Guerza-Soualah, Abdelkader Hanna, Hiba Azzeddine, Anne-Laure

Helbert, Francois Brisset, Thierry Baudin, Djamel Bradai

\section{To cite this version:}

Fairouze Guerza-Soualah, Abdelkader Hanna, Hiba Azzeddine, Anne-Laure Helbert, Francois Brisset, et al.. The deformation and recrystallization behaviour of an Mg-Dy alloy processed by plane strain compression. Materials Today Communications, 2020, 24, pp.101239. 10.1016/j.mtcomm.2020.101239 . hal-03010560

\section{HAL Id: hal-03010560 \\ https://hal.science/hal-03010560}

Submitted on 27 Nov 2020

HAL is a multi-disciplinary open access archive for the deposit and dissemination of scientific research documents, whether they are published or not. The documents may come from teaching and research institutions in France or abroad, or from public or private research centers.
L'archive ouverte pluridisciplinaire HAL, est destinée au dépôt et à la diffusion de documents scientifiques de niveau recherche, publiés ou non, émanant des établissements d'enseignement et de recherche français ou étrangers, des laboratoires publics ou privés. 


\title{
The deformation and recrystallization behavior of an Mg-Dy alloy processed by plane
} strain compression

Fairouze Guerza-Soualah ${ }^{1}$, Abdelkader Hanna ${ }^{2}$, Hiba Azzeddine ${ }^{2, *}$, Anne-Laure Helbert ${ }^{3}$, Francois Brisset ${ }^{3}$, Thierry Baudin ${ }^{3}$, Djamel Bradai ${ }^{1}$

${ }^{1}$ Faculty of Physics, University of Sciences and Technology Houari Boumediene, BP 32 ElAlia, 16111, Algiers, Algeria.

${ }^{2}$ Departments of Physics, University Mohamed Boudiaf, BP 166, 28000, M'sila Algeria

${ }^{3}$ Université Paris-Saclay, CNRS, Institut de chimie moléculaire et des matériaux d'Orsay, 91405 Orsay, France.

*Corresponding author: Dr. Hiba Azzeddine, hiba.azzeddine@univ-msila.dz

\begin{abstract}
The present study investigates the deformation and recrystallization behavior of an $\mathrm{Mg}$ 0.41Dy (wt. \%) alloy processed by plane strain compression (PSC) at room temperature (RT), 200 and $400{ }^{\circ} \mathrm{C}$ under strain rate of $10^{-4} \mathrm{~s}^{-1}$. PSC at RT and $200{ }^{\circ} \mathrm{C}$ cause the introduction of a high amount of deformation features like extension, contraction and double twins. Meanwhile, PSC at $400{ }^{\circ} \mathrm{C}$ is characterized by the occurrence of dynamic recrystallization. The changing in the microstructures affects the mechanical response of the alloy. The deformation texture was characterized by the formation of basal <0001> and prismatic $<10 \overline{1} 0>$ fiber. The texture intensity increases with increasing deformation temperature. The static recrystallization kinetics was investigated for all processed samples after subsequent annealing at $450{ }^{\circ} \mathrm{C}$ for a period time ranging from $30 \mathrm{~min}$ to 7 days. The evolution of grains size and microhardness depends strongly on the deformation temperatures. The recrystallization rate increases with increasing deformation temperature. The Avrami exponent of recrystallization $n$ was in the range of $0.9-0.26$ indicating that the recrystallization preferentially occurs along grain boundaries and within deformation features.
\end{abstract}

Keywords: Dynamic recrystallization; Static recrystallization; PSC; Mg-Dy alloy; Texture. 


\section{Introduction}

Magnesium ( $\mathrm{Mg}$ ) based alloys have a great potential to be used in diverse industrial applications such as automobiles, biomedical, telecommunication and aerospace due to its low density, high specific strength, good damping capacity, corrosion resistance and recyclability [1-3]. Despite that, Mg-based alloys suffer from limited formability at room temperature because of an insufficient number of activated slip systems and the formation of strong basal texture $[4,5]$. Thermo-mechanical processing and alloying elements have proven their efficiency to improve the formability and reduce the mechanical anisotropy of $\mathrm{Mg}$-based alloy, especially by microstructural modifications. Hot deformation allows the activation of prismatic and pyramidal $\langle\mathrm{c}+\mathrm{a}>$ slip systems and the occurrence of dynamic recrystallization (DRX) which improves the mechanical properties of Mg-based alloys by grain refinement [614]. Several mechanisms regrouped in two categories: discontinuous DRX (DDRX) and continuous DRX (CDRX) mechanisms have been proposed to explain the effect of DRX on the performance of Mg-based alloys. DDRX is characterized by nucleation and growth process derived by the stored energy during the deformation, while in CDRX mechanism the low grain boundaries (LAGB) are progressively transformed by absorbing dislocations to high grain boundaries (HAGB) and hence formed new grains $[11,15,16]$. However, is often reported that the recrystallization texture is not drastically changed regardless of the DRX mechanism [8, 17, 18].

Nowadays, rare earth (RE) alloying elements received special scientific attention due to its remarkable effect on the improving the mechanical anisotropy of Mg-based alloys through texture modifications during deformation and recrystallization as well [19, 20]. Different mechanisms were proposed in the literatures to explain the role of RE elements on texture weakening such as activation of non-basal slip systems by changing of stacking fault energy of Mg [21], Particle-Stimulated Nucleation (PSN) mechanism due to the presence of second particles [22] and the enhancement of solute drag of grain boundaries and dislocations [20, 23]. As a matter of fact, the texture modification or weakening of $\mathrm{Mg}$ - RE alloys depends strongly on the deformation conditions (processing type, temperature, strain and strain rate) and the choice of RE elements [24].

Up to now, the understanding of the impact of RE alloying elements on the evolution of mechanical properties during the deformation, recrystallization and grain growth processes is still not complete. Therefore, the effect of deformation temperature on the deformation and recrystallization behavior of binary $\mathrm{Mg}-0.41 \mathrm{Dy}$ (wt.\%) alloy is investigated in the present study. First, the deformation microstructure and texture of the alloy are characterized after 
processing by plane strain compression (PSC) at RT, 200 and $400{ }^{\circ} \mathrm{C}$ under strain rate of $10^{-4}$ $\mathrm{s}^{-1}$. Second, the recrystallized kinetics is investigated after subsequent annealing at $450{ }^{\circ} \mathrm{C}$ for time ranging between 30 minutes to 7 days.

\section{Experimental material and procedures}

The Mg-0.41Dy alloy was kindly supplied in as-cast condition by the Institute für Metallkunde und Metallphysik (IMM-RWTH) in Aachen, Germany. Accordingly, the alloy was prepared by induction melting and casting under a protective gas atmosphere of $\mathrm{Ar} / \mathrm{CO}_{2}$ and followed by annealing for $20 \mathrm{~h}$ at $420^{\circ} \mathrm{C}$.

Samples with dimensions of $14 \mathrm{~mm}$ (longitudinal direction, LD) x $10 \mathrm{~mm}$ (transverse direction, TD) x $6 \mathrm{~mm}$ (compression direction, $\mathrm{CD}$ ) were machined from the as-cast bloc. PSC tests were carried out at RT, 200 and $400{ }^{\circ} \mathrm{C}$ under strain rates of $10^{-4} \mathrm{~s}^{-1}$ using a conventional screw-driven ZWICK testing machine. A final true strain $\varepsilon=-1.2$ corresponding to $70 \%$ of reduction of thickness was achieved for all the samples. After PSC tests, the samples were directly quenched in water.

Annealing treatments were performed in a radiation furnace at $450{ }^{\circ} \mathrm{C}$ for time periods ranging from 30 min to 7 days.

The microstructure of the samples was investigated in the LD-TD plane using optical microscopy after grinding with progressively finer $\mathrm{SiC}$ paper followed by electropolish with 5:3-part ethanol and phosphoric acid for 30min under 3V applied voltage and etching at room temperature in an acetic-nital solution $\left(5 \% \mathrm{HNO}_{3}, 15 \%\right.$ acetic acid, $20 \%$ distilled water and $60 \%$ ethanol) for $3 \mathrm{~s}$.

EBSD measurements were performed after mechanical and ionic polishing using a Gatan PECS II system at a high voltage of $5 \mathrm{kV}$ for $15 \mathrm{~min}$. The EBSD data acquisition and analysis were undertaken using the TSL Orientation Imaging Microscopy, OIM ${ }^{\mathrm{TM}}$ software.

The scanned areas were $94 \times 58 \mu \mathrm{m}^{2}$ with a step size of $0.3 \mu \mathrm{m}$ for the sample processed at RT, $120 \times 107 \mu \mathrm{m}^{2}$ and $1080 \times 870 \mu \mathrm{m}^{2}$ with a step size of $1 \mu \mathrm{m}$ for the sample processed at 200 and $400{ }^{\circ} \mathrm{C}$, respectively. The grain size data were obtained using a grain tolerance angle of $5^{\circ}$ and the minimum grain size was chosen as 5 pixels. The confidence index (CI) which quantified the reliability of the indexed Kikuchi was taken higher than 0.05 to exclude poor quality pixels during the cleanup procedure [25].

Crystallographic texture was measured in the LD-TD plane using a Phillips X-ray texture diffractometer. A set of six pole figures $\{10 \overline{1} 0\},\{0002\},\{10 \overline{1} 1\},\{10 \overline{1} 2\},\{11 \overline{2} 0\}$, and 
$\{10 \overline{1} 3\}$ was measured to calculate the orientation distribution functions (ODF) using MTex software [26].

The Vickers microhardness was measured in the LD-TD plane using a SHIMADZU type HMV-2 tester. An average microhardness value was obtained using at least five indentations under a load of $100 \mathrm{~g}\left(\mathrm{Hv}_{0.1}\right)$ with a dwell time of $10 \mathrm{~s}$.

\section{Results and discussions}

\section{Initial microstructure}

Figure 1 shows the orientation imaging micrograph in inverse pole figure (IPF) and scanning electron microscopy (SEM) micrograph in the backscattering mode of the as-cast Mg-0.41Dy alloy, respectively. The as-cast microstructure exhibits large and coarse grains. In this case, the texture could be considered as random. Some casting twins are present as shown by arrows. Similar twins were observed in as-cast $\mathrm{Mg}-0.22 \mathrm{Gd}$ (wt.\%) alloy [27]. The SEM micrograph (Figure 1b) revealed the presence of the second phase identified as $\mathrm{Mg}_{41} \mathrm{Dy} 5$ phase. It was expected that the Mg- 0.41 alloy is a solid solution alloy since the binary phase diagram indicate that solubility of Dy is high in the Mg matrix (25.23\%, wt. \%) [28]. The annealing at $420{ }^{\circ} \mathrm{C}$ for $20 \mathrm{~h}$ followed the as casting process failed to dissolve this metastable phase.
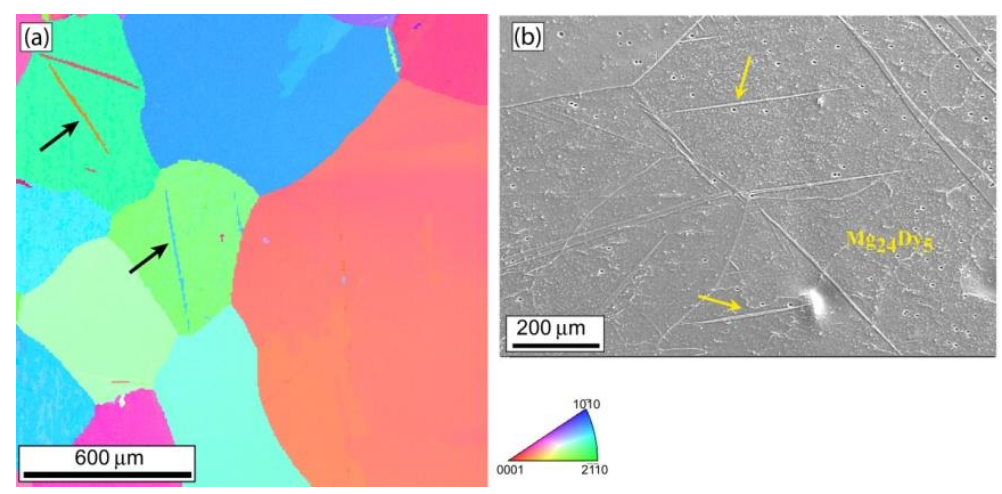

Figure 1: (a) IPF map and (b) SEM micrograph of as-cast Mg-0.41Dy alloy.

\section{PSC stress flow}

Figure 2 illustrates the true stress-strain curves of Mg-0.41Dy during PSC tests at RT, 200 and $400{ }^{\circ} \mathrm{C}$ under the strain rate of $10^{-4} \mathrm{~s}^{-1}$. It can be clearly seen that the mechanical response of Mg-0.41Dy alloy is different as function of deformation temperature and strongly related to the evolution of the deformation microstructure during the PSC test. 
The sample processed at RT exhibited higher flow. First, the stress shows a rapid increases due to the strain hardening to reach a maximum of $225 \mathrm{MPa}$ at $\varepsilon=-0.32$ and decreases up $\varepsilon=$ -0.6 to increases again. This secondary strain hardening (at $\varepsilon \sim-0.6$ ) is present in all processed samples (Figure 2) and it is usually seen in PSC processed Mg-based alloys and result from the result of the friction between the sample and channel-die [12, 14, 29, 30].

The first strain hardening is attributed to the accumulation of dislocations and twinning. Actually, the twin grain boundaries act as barriers to dislocation motions and then led to a work hardening $[31,32]$. Besides, the formation of "hard" orientations in the microstructure caused by the twinning can also increases the flow stress [33]. The flow curve of sample processed at $200{ }^{\circ} \mathrm{C}$ shows a continuous increase with increasing strain. While, sample processed at $400{ }^{\circ} \mathrm{C}$ exhibits the lower strain hardening (15 MPa at $\varepsilon=-0.02$ ) and gradually decreases to reach a relative steady state indicating a softening effect due to the dynamic recovery or dynamic recrystallization (DRX).

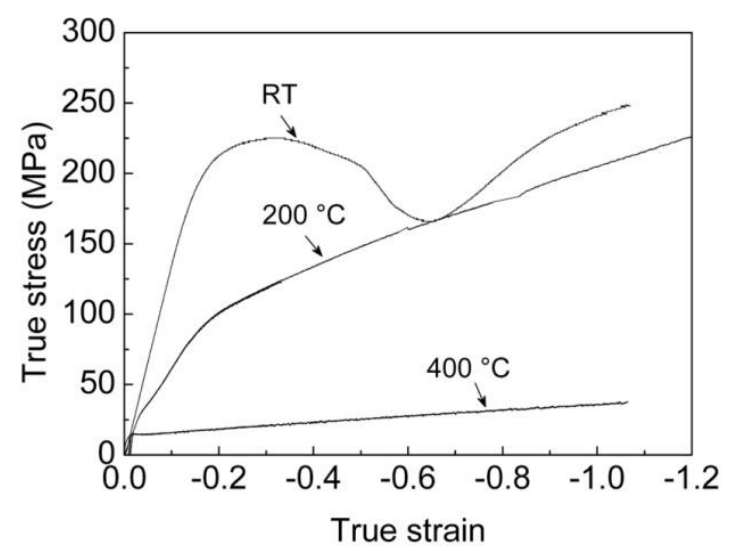

Figure 2: True stress-true strain curves of Mg-0.41Dy during PSC test at RT, 200 and $400{ }^{\circ} \mathrm{C}$ under strain rate of $10^{-4} \mathrm{~s}^{-1}$.

\section{Deformation microstructure}

Figure 3 shows the evolution of the deformation microstructure of Mg-0.41Dy after PSC test at RT, 200 and $400{ }^{\circ} \mathrm{C}$ under strain rate of $10^{-4} \mathrm{~s}^{-1}$, respectively. As expected, the microstructure of sample processed at RT exhibits large scale of deformation heterogeneities. Besides, the presence of high amount of twins shear bands could be also present as indicated by the highly distorted regions (dark regions as shown by arrow). The presence of shear bands is frequently observed in deformed Mg-based alloys and it appears in the form of dark streamlines inclined at $40^{\circ}$ to the loading direction [16, 34-36]. It was demonstrated that the shear bands were manifestly different in Mg-RE alloy compared to pure $\mathrm{Mg}$ and the $\mathrm{AZ31}$ 
alloy [10, 34]. The density of shear bands was higher in the deformed Mg-RE alloy and homogeneously distributed in the microstructure. The difference was attributed to the effect of RE element on the further activation of $\langle\mathrm{c}+\mathrm{a}\rangle$ pyramidal slip system and enhancement of contraction and double twins [10, 34].

The twin fraction decreases with increasing deformation temperatures and less heterogeneity can be noticed in Figure 3. It is well known that the activation of twins is less significant during deformation at high temperature [37]. The twins in sample processed at $200{ }^{\circ} \mathrm{C}$ have steppes like morphology. Similar twins structure was already reported in hot-rolled AZ31 alloy [35] and hot-compressed $\mathrm{Mg}-\mathrm{Zn}-\mathrm{Er}$ alloy [16]. The formation of such morphology depends on the strain level and the homogeneity of stress distribution inside the microstructure [16]. Figure 3c shows clearly the occurrence of DRX at high deformation temperature $\left(400{ }^{\circ} \mathrm{C}\right)$. The grains boundaries in sample processed at $400{ }^{\circ} \mathrm{C}$ are serrated and bulged which is an indicative of a nucleation and formation of new DRX grains. The bulging at the grain boundaries is characteristic of the DDRX type. The bulging of grain boundaries is due to the interaction between moving lattice dislocations and the grain boundaries and it was found stimulated when the non-basal slip like pyramidal $\langle\mathrm{c}+\mathrm{a}\rangle$ is activated [38].

The SEM micrographs of all processed samples show the presence of second particles. Unfortunately, their chemical composition identification was not possible because of their small size. However, it is obvious that their form and distribution differ significantly with increasing deformation temperature. At RT, the particles are small and well distributed in the microstructure. With increasing deformation temperature the particles are aligned along $45^{\circ}$ toward LD and have plate form. The volume fraction of the particles increases from $0.2 \%$ at RT and $200{ }^{\circ} \mathrm{C}$ to $2.3 \%$ in sample processed at $400{ }^{\circ} \mathrm{C}$. Previously, it was reported that HPT processing at RT of the same Mg-0.41Dy alloy causes the decomposition of the $\mathrm{Mg}_{24} \mathrm{Dy}_{5}$ second particles [39]. Moreover, annealing at 200 and $400{ }^{\circ} \mathrm{C}$ for $1 \mathrm{~h}$ of the HPT processed alloy result to more Dy element distribution [39].

Manifestly, the presences of twins have a great influence on the form and distribution of second phases in the processed sample. The high amount of twins in sample processed at RT prevents the second particles displacement. PSC at $200{ }^{\circ} \mathrm{C}$ results to less twins thus the second particles start to align $45^{\circ}$ toward LD as shown in Figure 3d. In case of processing at $400{ }^{\circ} \mathrm{C}$ when no twinning was observed a further changing in the form and distribution of second particles is clearly observed (Figure $3 \mathrm{~g}$ ). In addition, increasing the volume fraction of second particles during processing at $400{ }^{\circ} \mathrm{C}$ could be an indication of dynamic precipitation. 
In fact, it is often observed to occurrence of dynamic precipitation during hot processing of Mg-RE alloys [5, 40, 41].

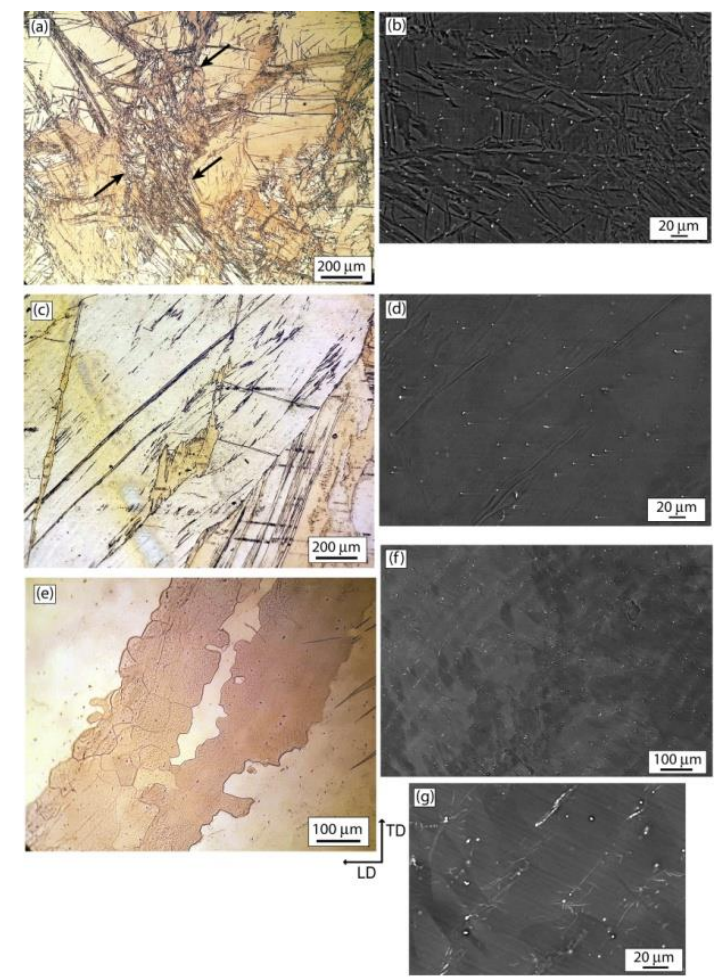

Figure 3: Deformation microstructures obtained by OM and SEM of Mg-0.41Dy after PSC test at: (a, b) RT, (c, d) 200 and (e-g) $400{ }^{\circ} \mathrm{C}$ under strain rate of $10^{-4} \mathrm{~s}^{-1}$.

It was recently reported that the discontinuous precipitation is entirely hindered by the grain boundaries of extension twins during ageing at $150{ }^{\circ} \mathrm{C}$ of AZ80 (Mg-8Al-0.5Zn, wt. \%) alloy [42]. In addition, the high dislocation density inside the twins can promotes the occurrence of continuous precipitation within the twins [42]. Consequently, the precipitates inside twins may block the dislocation motion and affect the mechanical properties of the alloy. In meantime, the presence of particles/precipitates can also affect the size and the total volume fraction of twins during deformation [43, 44]. It was indicated that the effective critical resolved shear stress (CRSS) for twin growth increases linearly with precipitate volume fraction [44].

Figure 4 shows some interesting features on the evolution of deformation microstructures using EBSD of Mg-0.41Dy alloy after PSC at RT, 200 and $400{ }^{\circ} \mathrm{C}$ under stain rate of $10^{-4} \mathrm{~s}^{-1}$, respectively.

The IPF map of Mg-0.41Dy alloy after PSC at RT and $200{ }^{\circ} \mathrm{C}$ (Figure $4 \mathrm{a}$ and $4 \mathrm{~d}$ ) shows complex twins formation and distribution. The purple line correspond to sub-boundaries $\left(2^{\circ}-\right.$ $5^{\circ}$ ), the white line presents low grain boundaries (LAGB) with misorientation between $5-15^{\circ}$ 
and the black line correspond to high grain boundaries $\left(\mathrm{HAGB},>15^{\circ}\right.$ ). The IPF map of the sample processed at RT presents some black zones resulting from the highly deformed areas in the sample. The identified twins in both samples are highlighted in Figures $4 \mathrm{~b}$ and $4 \mathrm{e}$ as: extension twin $86^{\circ}\langle 11 \overline{2} 0\rangle \pm 8^{\circ}$ (in green), contraction twin $56^{\circ}\langle 11 \overline{2} 0\rangle \pm 8^{\circ}$ (in blue), double twins $38^{\circ}\langle 11 \overline{2} 0\rangle \pm 8^{\circ}$ (in red) and $22^{\circ}\langle 11 \overline{2} 0\rangle \pm 8^{\circ}$ (in yellow).

Practically, all twins mode are present in both processed samples, except for $\left.22^{\circ}<11 \overline{2} 0\right\rangle$ seems less activated in sample processed at $200{ }^{\circ} \mathrm{C}$. The activation of the different twin modes in the same sample could be explained by the random texture of the as-cast Mg-0.41Dy alloy. It can be observed that extension twin $\left.86^{\circ}<11 \overline{2} 0\right\rangle$ and double twin $\left.38^{\circ}<11 \overline{2} 0\right\rangle$ are dominated in both microstructures. As known in deformed Mg-based alloys, the extension twin is the most twin present due to its low CRSS compared to the other twin modes [45]. In contrast, the presence of double twin is attributed to the rapid transformation of contraction twin to double twin during deformation processing [46].

It is recognized by looking inside the twins for both processed samples that contain high fraction of sub-boundaries (purple line). It is expected that these LAGBs will be progressively transformed to HAGBs and therefore should form the new structure of fine recrystallized grains as known by continuous recrystallization [11, 47, 48]. It was shown that the recrystallized grains can develop different orientations from those of the host twins and parent grains $[49,50]$.

One of the benefits of the activation of twin is the creation of new orientation. Figures $4 \mathrm{c}$ and $4 \mathrm{~d}$ show the $\{0002\}$ pole figure indicating the orientation between grains and twins in samples processed at RT and $200{ }^{\circ} \mathrm{C}$, respectively. The presence of extensive twinning causes the split of the basal pole approximately $\pm 15^{\circ}$ towards LD. Similar splitting was already reported in cold-rolled AZ31 alloy and was explained by the occurrence of double twining [34]. Moreover, it was speculated that the deformation heterogeneities like shear band could contributed to this splitting [45]. Generally, the splitting of basal pole reduces with increasing deformation temperature [45]. 


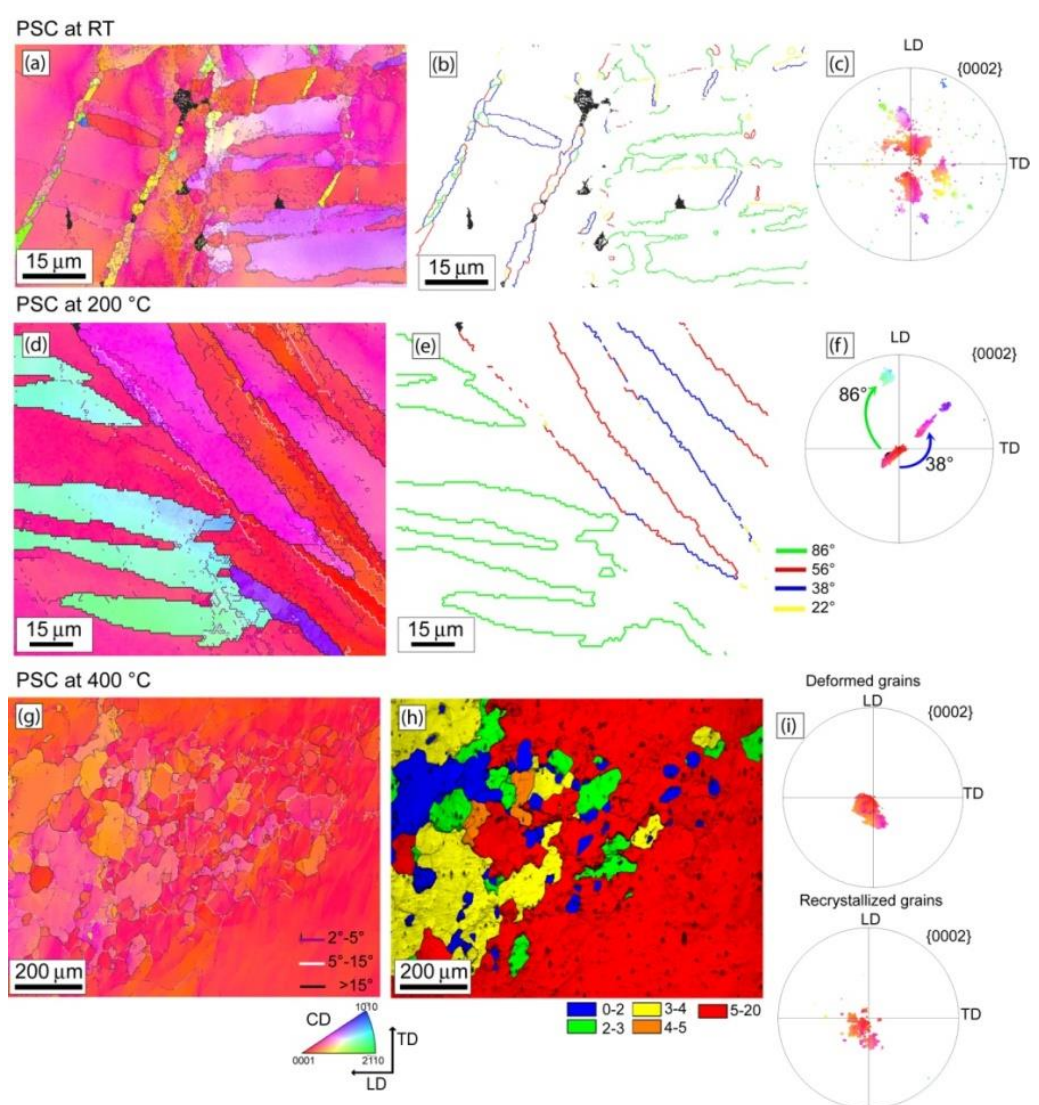

Figure 4: (a) IPF map, (b) map showing the presence of different twins and (c) $\{0002\}$ pole figure indicates the orientation between grains and twins for sample processed at RT. (d) IPF map, (e) map showing the presence of different twins and (f) $\{0002\}$ pole figure indicates the orientation between grains and twins for sample processed at $200{ }^{\circ} \mathrm{C}$. (g) IPF map, (h) GOS map and (i) the corresponding $\{0002\}$ pole figure of deformed and recrystallized grains in sample processed at $400{ }^{\circ} \mathrm{C}$.

The corresponding $\{0002\}$ pole figure of sample processed at $200{ }^{\circ} \mathrm{C}$ shown in Figure $4 \mathrm{f}$ demonstrated that extension twin change and create more different orientations than contraction or double twin. The $c$-axes of the extension twinned grains were tilted about $86^{\circ}$ from the basal plane of the parent grain which led to the formation of $\{0002\} / / \mathrm{LD}$ new orientation. In contrast, the compression and double twin cause only the spread of basal plane toward TD.

Figure $4 \mathrm{~g}$ shows the IPF map of the sample processed at $400{ }^{\circ} \mathrm{C}$. No twins were detected and it is cleary seen that few grains start to form in the large deformed grains. The recrystallized grains can be reconnaized using the grains orientation spread (GOS) approach where GOS is defined as the mean standard deviation of all the orientations inside a grain [51]. The GOS map shown in the Figure $4 \mathrm{~h}$ indicates that a few grains are recrystallized (blue one) as grains 
having GOS values less than $2^{\circ}$. The remains small grains have GOS values between 2 and $4^{\circ}$ which mean that they are dynamically recovered. The orientations of the deformed and recrystallized grains have the same basal texture as shown by the separated corresponding $\{0002\}$ pole figures in Figure 4i. Several studies repotred similar finding where the dynamically recrystallised grains developped the same orientation like the deformed one [52, 53].

It is worthnoting that even at high deformation temeprature $\left(400{ }^{\circ} \mathrm{C}\right)$ and low strain rate $\left(10^{-4}\right.$ $\mathrm{s}^{-1}$ ) the present $\mathrm{Mg}-0.41 \mathrm{Dy}$ alloy shows low fraction of dynamic recrystallization in comparaison with conventional AZ31 [9, 33] or even ternary Mg-RE alloy [5]. It was observed that the dynamic recrystallization was inhibited in $\mathrm{Mg}-1.5 \mathrm{Gd}$ (wt. \%) compared to AZ31 alloy during hot PSC and it was explain by the higher stored energy devellopted in $\mathrm{Mg}$ $1.5 \mathrm{Gd}$ alloy [33]. The retardation of DRX can be also result from the solute segregation to grain boundaries (pinning effect) [54] and the change in the recovery behavior caused by the reduction in the stacking fault energy [55].

\section{Deformation texture}

Figures 5 presents the evolution of the texture of $\mathrm{Mg}-0.41 \mathrm{Dy}$ alloy after PSC at RT, 200 and $400{ }^{\circ} \mathrm{C}$ under a strain rate of $10^{-4} \mathrm{~s}^{-1}$ in terms of recalculated $\{0002\}$ and $\{10 \overline{1} 0\}$ pole figure, respectively. As can be seen, PSC processing leads to the formation of two fibers: basal texture $<0001>/ / \mathrm{CD}\left(\varphi_{1}=0-360^{\circ}, \Phi=0^{\circ}, \varphi_{2}=0^{\circ}\right)$ and weak $<10 \overline{1} 0>/ / \mathrm{CD}\left(\varphi_{1}=0-360^{\circ}, \Phi\right.$ $\left.=90^{\circ}, \varphi 2=30^{\circ}\right)$. Similar texture evolution was previuosly reported in hot-compressed WE54 (Mg-4.9Y-4.2Nd-0.56Zr, wt.\%) alloy and binary cold proccesed $\mathrm{Mg}-1.33 \mathrm{La}$ (wt. \%) alloy by PSC [5, 14]. However, some difference can be noticed as function of deformation temepratures. First, the texture intensity increases significantly with increasing deformation temperature. Second, it can be shown that processing at RT lead to the development of only a weak basal $<0001>/ / \mathrm{CD}$ and a very weak prismatic $<10 \overline{1} 0>/ / \mathrm{CD}$ fiber. The weak texture can be attributed to the presence of high scale of deformation henetrogities resulting to the development of wide range of orientations $[24,56]$. In contrast, the prismatic $<10 \overline{1} 0\rangle / / \mathrm{CD}$ fiber despaired and a net spliting of basal pole towared LD can be notice in sample processed at $200{ }^{\circ} \mathrm{C}$. The split of basal pole toward LD was attributed to the activation of twinnig and the pyramidal $<c+$ a $>$ slip [35]. Moreover, the recalculated $\{0002\}$ pole figure shows the presence of two texture components <0001> // LD and <0001> // TD, respectively. The development of both texture components result from desorientation resultated from the activation of twins as shown in Figures $4 \mathrm{e}$ and $4 \mathrm{f}$. This finding is supported by the similar 
development of deformation texture of AZ31 alloy [57]. The prismatic <10 $\overline{1} 0>/ / \mathrm{CD}$ fiber seems to appeared again after processing at $400{ }^{\circ} \mathrm{C}$. However, Figure 6 shows cleary that the fibers are not continuous espacially for sample procesed at 200 and $400{ }^{\circ} \mathrm{C}$ where the high intensities of the fibers are more concentrated around specific orientations. For exemple, for sample processed at $400{ }^{\circ} \mathrm{C}$ the maximum intensity $(\sim 21 \mathrm{mrd})$ of basal <0001> fiber is located at $\left(270^{\circ}, 0^{\circ}, 0^{\circ}\right)$. While the maximum of $\left\langle 10 \overline{1} 0>/ / \mathrm{CD}\right.$ fiber is located at $\left(50^{\circ}, 90^{\circ}\right.$, $\left.30^{\circ}\right),\left(115^{\circ}, 90^{\circ}, 30^{\circ}\right),\left(230^{\circ}, 90^{\circ}, 30^{\circ}\right)$ and $\left(295,90^{\circ}, 30^{\circ}\right)$, respectevely. Based on the evolution of deformation microstructure at $400{ }^{\circ} \mathrm{C}$, the resulted texture is attributed to the DRX and the presence of the second particule. Howerver, it is known that DRX led to the weakenenig of deformation texture in Mg-RE alloy. As evidenced in Figure $4 \mathrm{~h}$ the DRX is strongly retained during deformation at $400{ }^{\circ} \mathrm{C}$.
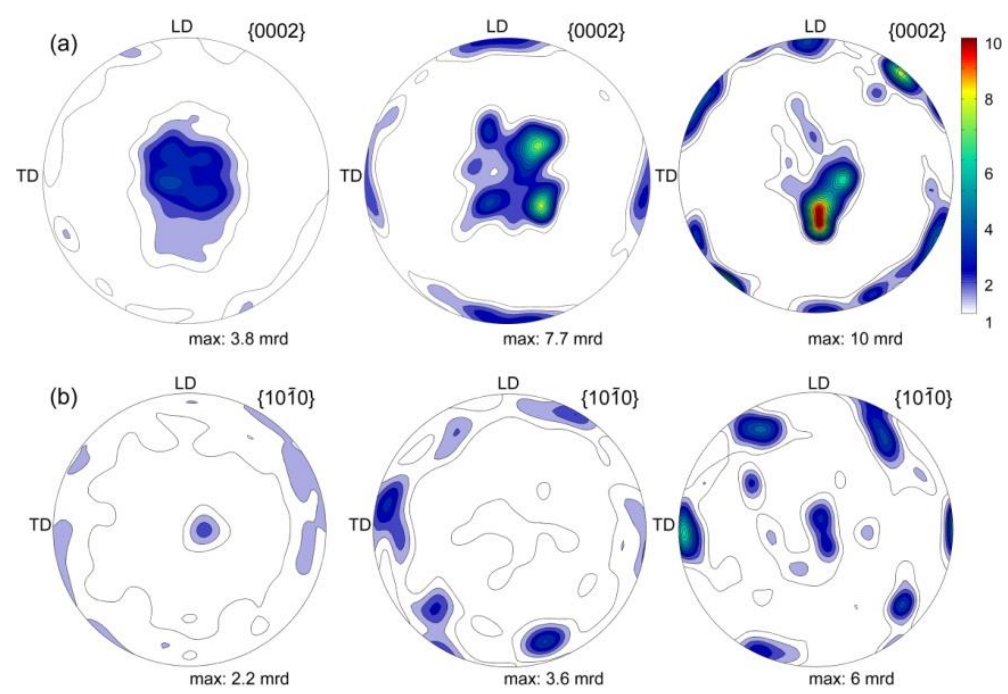

Figure 5: Recalculated (a) $\{0002\}$ and (b) $\{10 \overline{1} 0\}$ pole figure of Mg-0.41Dy alloy after PSC at RT, 200 and $400{ }^{\circ} \mathrm{C}$ under strain rate of $10^{-4} \mathrm{~s}^{-1}$, respectively. 

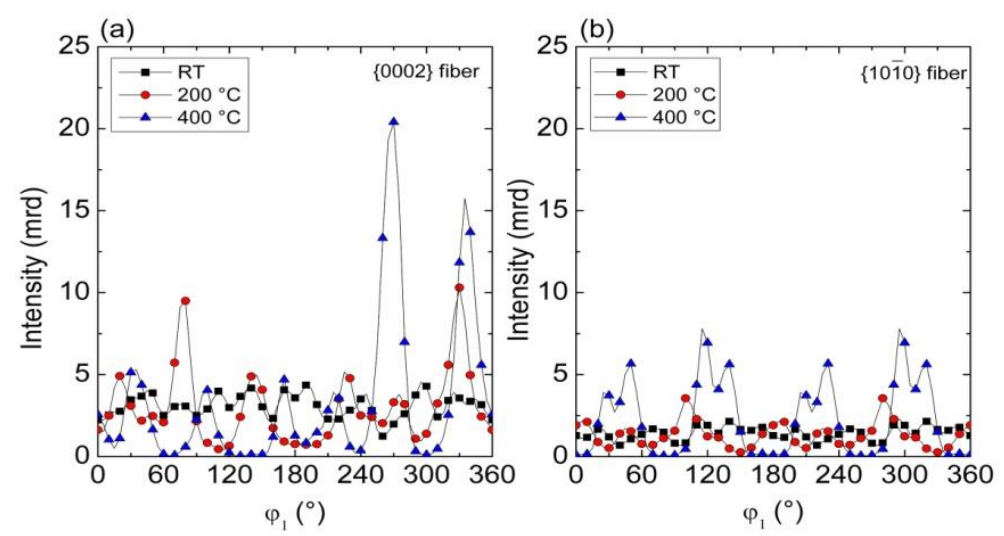

Figure 6: Evolution of (a) $\{0002\}$ and (b) $\{10 \overline{1} 0\}$ fiber as function of $\varphi_{1}$ angle of Mg-0.41Dy processed at RT, 200 and $400{ }^{\circ} \mathrm{C}$ under strain rate of $10^{-4} \mathrm{~s}^{-1}$.

It was suggested that the presence of second particle have more effect on texture weakening during hot compression rather than the concentration of $\mathrm{RE}$ element on the $\mathrm{Mg}$ matrix [58]. However, following the present finding, the dynamic precipitation during PSC and uniaxial compression at $300{ }^{\circ} \mathrm{C}$ of WE54 alloy show no effect on altering the deformation texture [5]. Moreover, the presence of second phase is not necessary for weakening the deformation texture since several solid solution Mg-RE alloys exhibit weak texture [59, 60].

\section{Static recrystallization}

Figure 7-9 illustrate the evolution of the microstructure of the processed Mg-0.41Dy at RT, 200 and $400{ }^{\circ} \mathrm{C}$ and subsequent annealed at $450{ }^{\circ} \mathrm{C}$ to 7 days, respectively. Interesting to note that sample processed at $400{ }^{\circ} \mathrm{C}$ still partially recrystallized after annealing for $30 \mathrm{~min}$, while both processed samples at RT and $200{ }^{\circ} \mathrm{C}$ show a typical recrystallized microstructure with equiaxe grain distribution. In meantime, increasing annealing time causes a drastic coarsening of grain for sample processed at $400{ }^{\circ} \mathrm{C}$ as shown in Figure 9. The evolution of average grain size as function of annealing time for samples processed at RT and $200{ }^{\circ} \mathrm{C}$ is shown in Figure 10. The average grain size of sample processed at $400{ }^{\circ} \mathrm{C}$ could not be calculated because of lack of statistic since only few grains can be detected in the microstructures, as shown in Figure 9. 


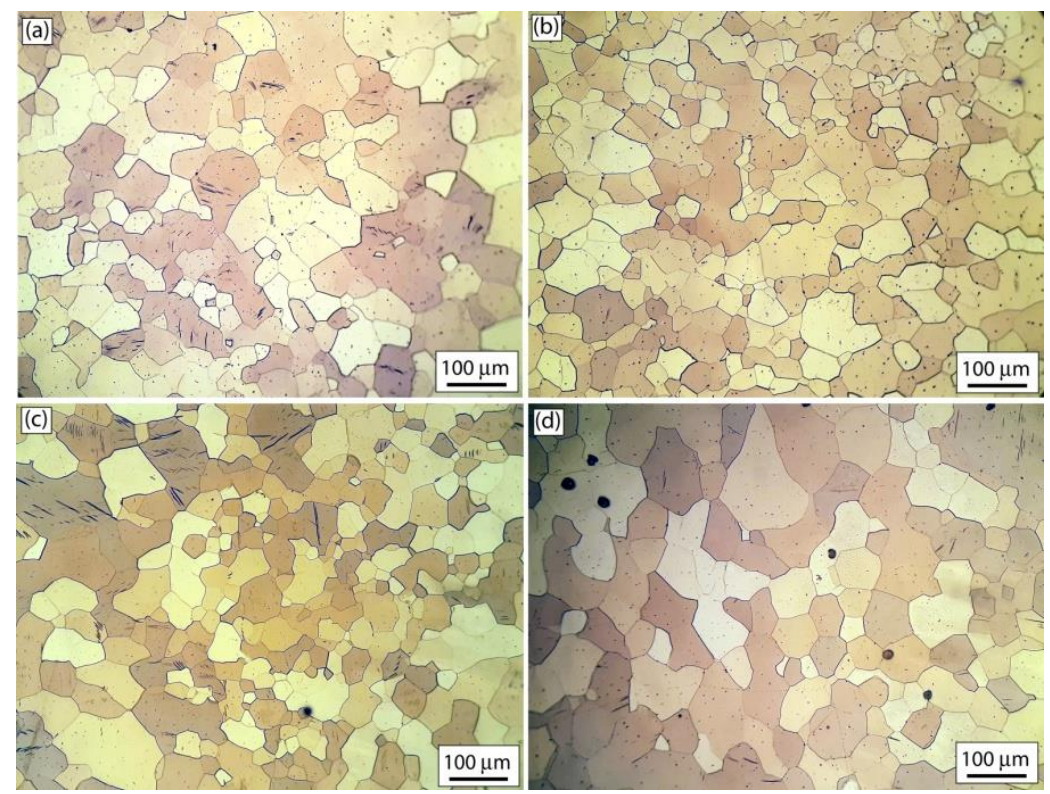

Figure 7: Evolution of recrystallization microstructure of $\mathrm{Mg}-0.41 \mathrm{Dy}$ processed at RT and annealed at $450{ }^{\circ} \mathrm{C}$ to : (a) $30 \mathrm{~min}$, (b) $10 \mathrm{~h}$, (c) $24 \mathrm{~h}$ and (d) 7 days.
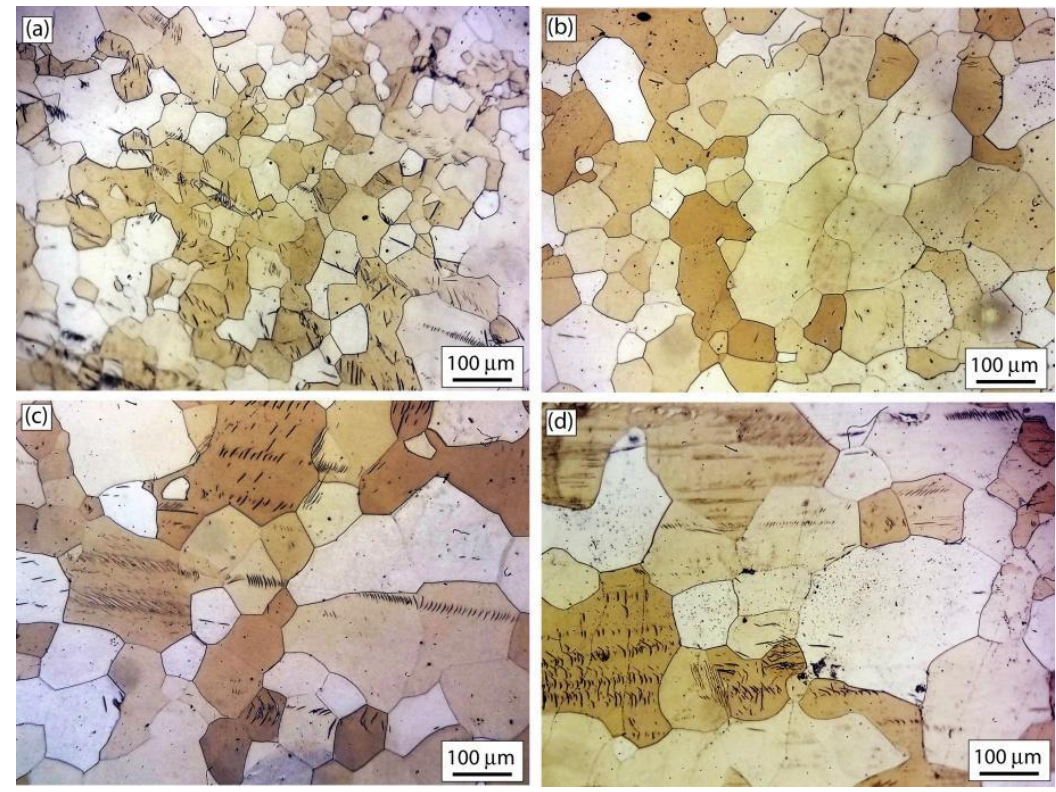

Figure 8: Evolution of recrystallization microstructure of $\mathrm{Mg}-0.41 \mathrm{Dy}$ processed at $200{ }^{\circ} \mathrm{C}$ and annealed at $450{ }^{\circ} \mathrm{C}$ to : (a) $30 \mathrm{~min}$, (b) $24 \mathrm{~h}$, (c) 3 days and (d) 7 days. 

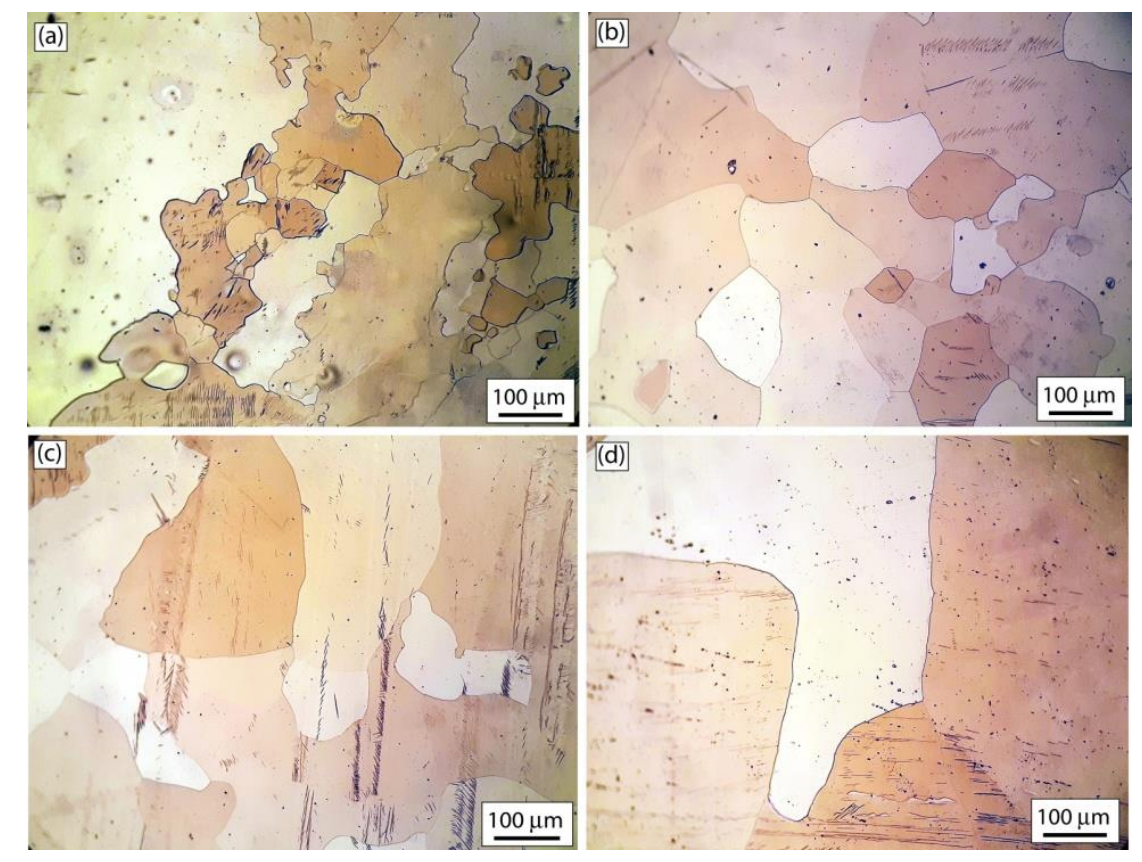

Figure 9: Evolution of recrystallization microstructure of $\mathrm{Mg}-0.41 \mathrm{Dy}$ processed at $400{ }^{\circ} \mathrm{C}$ and annealed at $450{ }^{\circ} \mathrm{C}$ to : (a) $30 \mathrm{~min}$, (b) $10 \mathrm{~h}$, (c) 3 days and (d) 7 days.

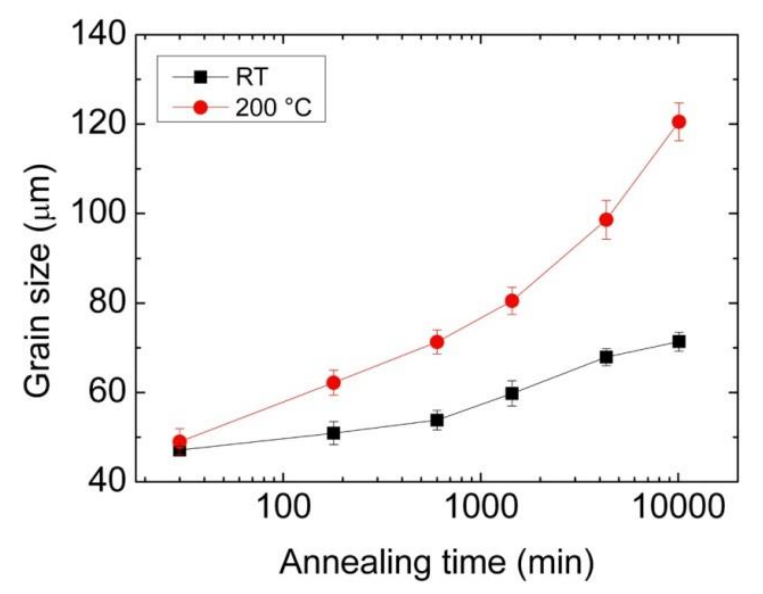

Figure 10: Evolution of grain size as function of annealing time of $\mathrm{Mg}-0.41 \mathrm{Dy}$ processed at RT and $200{ }^{\circ} \mathrm{C}$, respectively.

As can be notice, the rate of increasing grain size increase with increasing deformation temperature. The average grain size of sample processed at RT increases slowly from $47 \pm 0.8$ $\mu \mathrm{m}$ after annealing for $30 \mathrm{~min}$ to $71 \pm 2.1 \mu \mathrm{m}$ after 7 days. While, processing at $200{ }^{\circ} \mathrm{C}$ lead to rapid increases from $49 \pm 2.9 \mu \mathrm{m}$ after $30 \mathrm{~min}$ to $120.5 \pm 4.2 \mu \mathrm{m}$ after 7 days of annealing.

It is expected that the stored energy in sample processed at lower deformation temperatures and higher strains will be higher and thereby increases the rate of recrystallization [61]. 
However, this is not the case in the present alloy. The rate of evolution of grains size is lower with decreasing the deformation temperature.

The presence of second particles is another factor could retard the recrystallization by pinning the migration of grain boundaries. However, it can be speculated that during the deformation at $400{ }^{\circ} \mathrm{C}$ the solute drag and Zener pinning would be negligible consequently the high rate of grain growth shown in Figure 9. The evolution of static recrystallization is rather faster at 400 ${ }^{\circ} \mathrm{C}$ indicating that DRX plays a significant role in this case.

Actually, the homogenous and fine grains distribution in sample processed at RT is attributed to the presence of high deformation mode such as shear band and twining as shown in Figure 2 compared to sample processed at 200 and $400{ }^{\circ} \mathrm{C}$. It was evidenced that the recrystallized grains inside the twin do not grow beyond twin boundaries due to their low mobility [62].

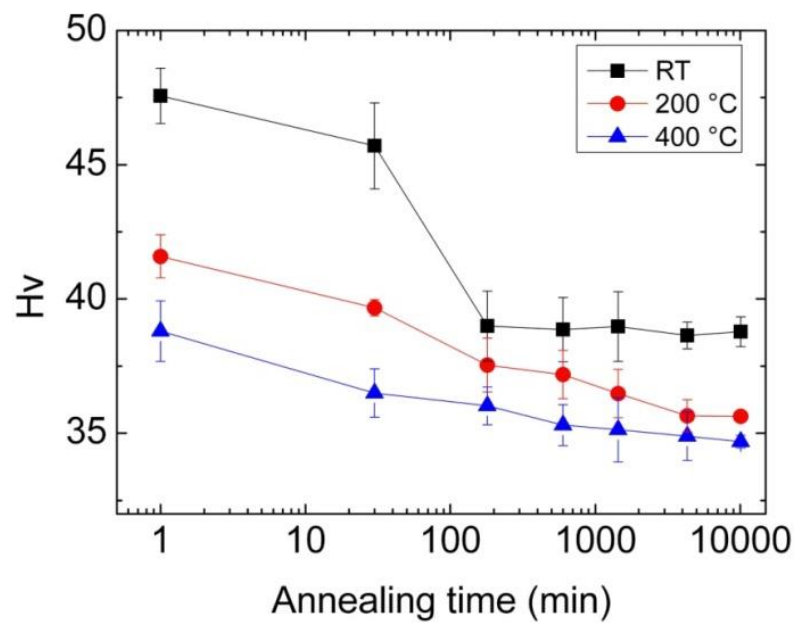

Figure 11: Evolution of microhardness as function of annealing time of Mg-0.41Dy processed at RT, 200 and $400{ }^{\circ} \mathrm{C}$, respectively.

Figure 11 shows the variation of microhardness as function of annealing time of $\mathrm{Mg}-0.41 \mathrm{Dy}$ processed at RT, 200 and $400{ }^{\circ} \mathrm{C}$, respectively. It is obvious that the sample processed at RT has different tendency than those processed at 200 and $400{ }^{\circ} \mathrm{C}$. First, the $\mathrm{Hv}$ values decrease slowly between annealing for $30 \mathrm{~min}$ and $3 \mathrm{~h}$ followed by rapid decrease to reach a value of $38.86 \pm 1.2 \mathrm{Hv}$ after $10 \mathrm{~h}$ of annealing and then a steady state is reached $(38.7 \pm 0.5 \mathrm{Hv}$ after 7 days of annealing). In contrast, the $\mathrm{Hv}$ values of samples processed at 200 and $400{ }^{\circ} \mathrm{C}$ show a continuous decrease with increasing annealing time indicate a continuous softening of the microstructure. As can be seen the $\mathrm{Hv}$ values depend strongly on the deformation temperature. It is decease with increasing deformation temperature. 


\section{Static recrystallization kinetics}

The recrystallization kinetics of deformed alloy can be investigated using the Johnson-MehlAvrami-Kolmogorov (JMAK) model [63]:

$$
X=1-\exp \left(-k t^{n}\right)
$$

where $X$ is the recrystallized fraction, $k$ a pre-exponential constant and $n$ is the Avrami exponent.

The recrystallized fraction can be estimated by mean grains size or Hv values following the equations:

$$
X_{d}=\frac{d_{t}-d_{0}}{d_{f}-d_{0}}
$$

where $d_{t}$ is the mean grain size of the annealed sample at time $t, d_{0}$ the mean grain size of the deformed alloy and $d_{f}$ the mean grain size of the full recrystallized alloy ( $t=7$ days). It is to be noted that $d_{0}$ was taken from samples annealed for $30 \mathrm{~min}$.

$$
X_{H v}=\frac{H v_{0}-H v_{t}}{H v_{0}-H v_{f}}
$$

where $H v_{0}$ is the microhardness of the deformed sample, $H v_{f}$ the microhardness of the recrystallized sample and $H v_{t}$ the microhardness of the annealed sample at time $t$.

The $n$ avrami exponent can be calculated by the linear relationship from the equation (1):

$$
\ln \ln \left(\frac{1}{1-X}\right)=\ln k+n \ln t
$$

The plots of $\ln \ln \left(\frac{1}{1-X}\right)$ as function of $\ln t$ are shown in Figure 12. The $n$ values for the annealed samples are shown in the graphs. The $n$ value of sample processed at RT calculated from mean grain size was close to the unity $(n=0.91) . n=0.5$ was found for sample processed at $200{ }^{\circ} \mathrm{C}$. Both techniques, $X_{d}$ or $X_{H v}$ give the same $n$ value. For sample processed at $400{ }^{\circ} \mathrm{C}$ the $n$ value decreases to $n=0.26$. In the literature $n=1$ indicate that onedimensional grain growth occurred due to migration of HAGB [64]. It was reported that the lower $n$ value can be attributed to the non-random recrystallization sites present in the deformed alloy [61]. In this case, the recrystallization preferentially occurs along grain boundaries and within twins and shear bands. This is in good agreement with the evolution of deformation microstructure. 

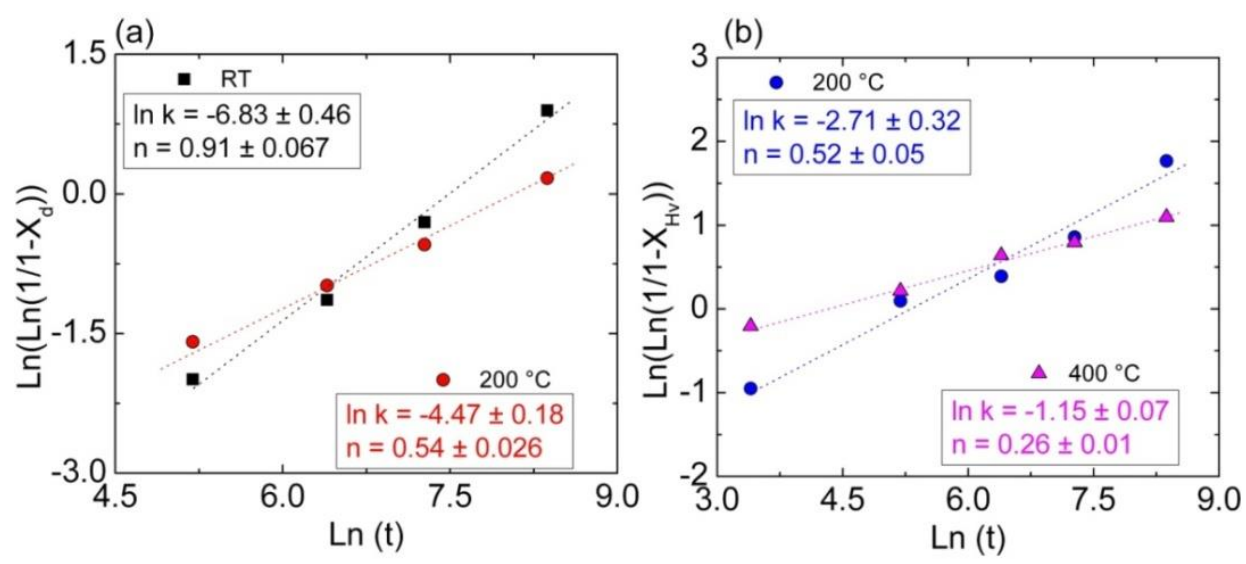

Figure 12: Evolution $\ln \ln \left(\frac{1}{1-X}\right)$ as function of $\ln t$ for the processed sample at RT, 200 and $400{ }^{\circ} \mathrm{C}$.

The $n$ values were reported to be as $0.68,0.70$ and 1.02 for hot-rolled Mg-Al-Zn-Mn-Ca alloy and annealed at 200, 300 and $450{ }^{\circ} \mathrm{C}$, respectively [65]. Also, the $n$ values were in range of 1.6-3.4 for cold rolled AZ31 alloy [66]. It is seems that $n$ value increases with increasing annealing temperature and deformation strain $[65,66]$. In the present work the $n$ value is sensitive to the deformation condition where it decreases with increasing deformation temperature.

\section{Conclusions}

- The binary Mg-0.41Dy alloy was processed by PSC at RT, 200 and $400{ }^{\circ} \mathrm{C}$ under strain rate of $10^{-4} \mathrm{~s}^{-1}$.

- The deformation and recrystallization microstructures and texture have a strong dependency on the deformation temperature.

- PSC at RT exhibits a large scale of heterogeneities composed of various mode of twining, i.e. extension, contraction and double twins. Less heterogeneity was observed during PSC at $200{ }^{\circ} \mathrm{C}$ and the twins have steppes structure morphology. While PSC at $400{ }^{\circ} \mathrm{C}$ led to the occurrence of dynamic recrystallization. However, the fraction of dynamically recrystallized grains was low compared to conventional Mg-based alloys due to the effect of the RE element and the presence of the second phase.

- The texture was characterized by the formation of basal $\{0001\}$ and prismatic $\{10 \overline{1} 0\}$ fibers. The texture intensity increases with increasing deformation temperature.

- The rate of evolution of grains size during annealing at $450{ }^{\circ} \mathrm{C}$ was lower with decreasing the deformation temperature. 
- The Avrami exponent of recrystallization $n$ was in the range of 0.9-0.26 indicating that the recrystallization preferentially occurs along grain boundaries and within deformation features such as twins.

\section{References}

[1] J. Hirsch, T. Al-Samman, Superior light metals by texture engineering: Optimized aluminum and magnesium alloys for automotive applications, Acta Materialia, 61 (2013) 818843. DOI: https://doi.org/10.1016/j.actamat.2012.10.044.

[2] S. You, Y. Huang, K.U. Kainer, N. Hort, Recent research and developments on wrought magnesium alloys, Journal of Magnesium and Alloys, 5 (2017) 239-253. DOI: https://doi.org/10.1016/j.jma.2017.09.001.

[3] A. Atrens, S. Johnston, Z. Shi, M.S. Dargusch, Viewpoint - Understanding Mg corrosion in the body for biodegradable medical implants, Scripta Materialia, 154 (2018) 92-100. DOI: https://doi.org/10.1016/j.scriptamat.2018.05.021.

[4] M.H. Yoo, Slip, twinning, and fracture in hexagonal close-packed metals, Metallurgical Transactions A, 12 (1981) 409-418. DOI: 10.1007/BF02648537.

[5] H. Azzeddine, D. Bradai, On the texture and grain growth in hot-deformed and annealed WE54 alloy, International Journal of Materials Research, 103 (2012) 1351-1360. DOI: $10.3139 / 146.110768$.

[6] M.R. Barnett, Influence of deformation conditions and texture on the high temperature flow stress of magnesium AZ31, Journal of Light Metals, 1 (2001) 167-177. DOI: https://doi.org/10.1016/S1471-5317(01)00010-4.

[7] K. Matsubara, Y. Miyahara, Z. Horita, T.G. Langdon, Developing superplasticity in a magnesium alloy through a combination of extrusion and ECAP, Acta Materialia, 51 (2003) 3073-3084. DOI: https://doi.org/10.1016/S1359-6454(03)00118-6.

[8] T. Al-Samman, G. Gottstein, Dynamic recrystallization during high temperature deformation of magnesium, Materials Science and Engineering: A, 490 (2008) 411-420. DOI: https://doi.org/10.1016/j.msea.2008.02.004.

[9] S. Abdessameud, H. Azzeddine, B. Alili, D. Bradai, Grain growth in AZ31 alloy after uniaxial compression, Transactions of Nonferrous Metals Society of China, 20 (2010) 22152222. DOI: https://doi.org/10.1016/S1003-6326(10)60631-0.

[10] S. Sandlöbes, I. Schestakow, S.B. Yi, S. Zaefferer, J.Q. Chen, M. Friák, J. Neugebauer, D. Raabe, The Relation between Shear Banding, Microstructure and Mechanical Properties in 
$\mathrm{Mg}$ and Mg-Y Alloys, Materials Science Forum, 690 (2011) 202-205. DOI: 10.4028/www.scientific.net/MSF.690.202.

[11] T. Al-Samman, K.D. Molodov, D.A. Molodov, G. Gottstein, S. Suwas, Softening and dynamic recrystallization in magnesium single crystals during c-axis compression, Acta Materialia, 60 (2012) 537-545. DOI: https://doi.org/10.1016/j.actamat.2011.10.013.

[12] H. Azzeddine, D. Bradai, On some aspects of compressive properties and serrated flow in Mg-Y-Nd-Zr alloy, Journal of Rare Earths, 31 (2013) 804-810. DOI: https://doi.org/10.1016/S1002-0721(12)60362-7.

[13] S.K. Mishra, S.M. Tiwari, J.T. Carter, A. Tewari, Texture evolution during annealing of AZ31 Mg alloy rolled sheet and its effect on ductility, Materials Science and Engineering: A, 599 (2014) 1-8. DOI: https://doi.org/10.1016/j.msea.2014.01.034.

[14] D. Elfiad, Y.I. Bourezg, H. Azzeddine, D. Bradai, Investigation of texture, microstructure, and mechanical properties of a magnesium-lanthanum alloy after thermomechanical processing, International Journal of Materials Research, 107 (2016) 315-323. DOI: $10.3139 / 146.111347$.

[15] S.E. Ion, F.J. Humphreys, S.H. White, Dynamic recrystallisation and the development of microstructure during the high temperature deformation of magnesium, Acta Metallurgica, 30 (1982) 1909-1919. DOI: https://doi.org/10.1016/0001-6160(82)90031-1.

[16] J.-x. Liu, K. Liu, W.-b. Du, S.-b. Li, Z.-h. Wang, X. Du, C.-c. Sun, Effect of temperature on microstructure and texture evolution of $\mathrm{Mg}-\mathrm{Zn}-\mathrm{Er}$ alloy during hot compression, Transactions of Nonferrous Metals Society of China, 28 (2018) 2214-2225. DOI: https://doi.org/10.1016/S1003-6326(18)64866-6.

[17] A. Hanna, H. Azzeddine, R. Lachhab, T. Baudin, A.-L. Helbert, F. Brisset, Y. Huang, D. Bradai, T.G. Langdon, Evaluating the textural and mechanical properties of an Mg-Dy alloy processed by high-pressure torsion, Journal of Alloys and Compounds, 778 (2019) 61-71. DOI: https://doi.org/10.1016/j.jallcom.2018.11.109.

[18] X. Zeng, P. Minárik, P. Dobroň, D. Letzig, K.U. Kainer, S. Yi, Role of deformation mechanisms and grain growth in microstructure evolution during recrystallization of $\mathrm{Mg}-\mathrm{Nd}$ based alloys, Scripta Materialia, 166 (2019) 53-57. DOI: https://doi.org/10.1016/j.scriptamat.2019.02.045.

[19] A. Imandoust, C.D. Barrett, T. Al-Samman, M.A. Tschopp, E. Essadiqi, N. Hort, H. El Kadiri, Unraveling Recrystallization Mechanisms Governing Texture Development from Rare-Earth Element Additions to Magnesium, Metallurgical and Materials Transactions A, 49 (2018) 1809-1829. DOI: 10.1007/s11661-018-4520-8. 
[20] I.-H. Jung, M. Sanjari, J. Kim, S. Yue, Role of RE in the deformation and recrystallization of $\mathrm{Mg}$ alloy and a new alloy design concept for $\mathrm{Mg}-\mathrm{RE}$ alloys, Scripta Materialia, 102 (2015) 1-6. DOI: https://doi.org/10.1016/j.scriptamat.2014.12.010.

[21] S. Sandlöbes, S. Zaefferer, I. Schestakow, S. Yi, R. Gonzalez-Martinez, On the role of non-basal deformation mechanisms for the ductility of $\mathrm{Mg}$ and $\mathrm{Mg}-\mathrm{Y}$ alloys, Acta Materialia, 59 (2011) 429-439. DOI: https://doi.org/10.1016/j.actamat.2010.08.031.

[22] T. Al-Samman, Modification of texture and microstructure of magnesium alloy extrusions by particle-stimulated recrystallization, Materials Science and Engineering: A, 560 (2013) 561-566. DOI: https://doi.org/10.1016/j.msea.2012.09.102.

[23] C.D. Barrett, A. Imandoust, H. El Kadiri, The effect of rare earth element segregation on grain boundary energy and mobility in magnesium and ensuing texture weakening, Scripta Materialia, 146 (2018) 46-50. DOI: https://doi.org/10.1016/j.scriptamat.2017.11.004.

[24] A. Imandoust, C.D. Barrett, T. Al-Samman, K.A. Inal, H. El Kadiri, A review on the effect of rare-earth elements on texture evolution during processing of magnesium alloys, Journal of Materials Science, 52 (2017) 1-29. DOI: 10.1007/s10853-016-0371-0.

[25] Y. Mikami, K. Oda, M. Kamaya, M. Mochizuki, Effect of reference point selection on microscopic stress measurement using EBSD, Materials Science and Engineering: A, 647 (2015) 256-264. DOI: https://doi.org/10.1016/j.msea.2015.09.004.

[26] F. Bachmann, R. Hielscher, H. Schaeben, Texture Analysis with MTEX - Free and Open Source Software Toolbox, Solid State Phenomena, 160 (2010) 63-68. DOI: 10.4028/www.scientific.net/SSP.160.63.

[27] N. Stanford, D. Atwell, M.R. Barnett, The effect of Gd on the recrystallisation, texture and deformation behaviour of magnesium-based alloys, Acta Materialia, 58 (2010) 67736783. DOI: https://doi.org/10.1016/j.actamat.2010.09.003.

[28] L.L. Rokhlin, Magnesium Alloys Containing Rare Earth Metals: Structure and Properties, Taylor \& Francis, 2003.

[29] X. Li, T. Al-Samman, S. Mu, G. Gottstein, Texture and microstructure development during hot deformation of ME20 magnesium alloy: Experiments and simulations, Materials $\begin{array}{llllll}\text { Science } & \text { and } \text { Engineering: A, } 528 \text { (2011) 7915-7925. DOI: }\end{array}$ https://doi.org/10.1016/j.msea.2011.07.010.

[30] T. Al-Samman, Effect of heavy metal impurities in secondary $\mathrm{Mg}$ alloys on the microstructure and mechanical properties during deformation, Materials \& Design (19802015), 65 (2015) 983-988. DOI: https://doi.org/10.1016/j.matdes.2014.10.025. 
[31] M.R. Barnett, Z. Keshavarz, A.G. Beer, D. Atwell, Influence of grain size on the compressive deformation of wrought Mg-3Al-1Zn, Acta Materialia, 52 (2004) 5093-5103. DOI: https://doi.org/10.1016/j.actamat.2004.07.015.

[32] T. Al-Samman, B. Ahmad, G. Gottstein, Uniaxial and Plane Strain Compression Behaviour of Magnesium Alloy AZ31: A Comparative Study, Materials Science Forum, 550 (2007) 229-234. DOI: 10.4028/www.scientific.net/MSF.550.229.

[33] N. Stanford, M.D. Callaghan, B. de Jong, The effect of rare earth elements on the behaviour of magnesium-based alloys: Part 1-Hot deformation behaviour, Materials Science and Engineering: A, 565 (2013) 459-468. DOI: https://doi.org/10.1016/j.msea.2012.12.023.

[34] M.R. Barnett, M.D. Nave, C.J. Bettles, Deformation microstructures and textures of some cold rolled Mg alloys, Materials Science and Engineering: A, 386 (2004) 205-211. DOI: https://doi.org/10.1016/j.msea.2004.07.030.

[35] L.W.F. Mackenzie, M. Pekguleryuz, The influences of alloying additions and processing parameters on the rolling microstructures and textures of magnesium alloys, Materials

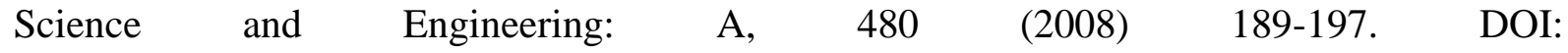
https://doi.org/10.1016/j.msea.2007.07.003.

[36] S.M. Fatemi-Varzaneh, A. Zarei-Hanzaki, J.M. Cabrera, Shear banding phenomenon during severe plastic deformation of an AZ31 magnesium alloy, Journal of Alloys and Compounds, 509 (2011) 3806-3810. DOI: https://doi.org/10.1016/j.jallcom.2011.01.019.

[37] C. Tomé, S.R. Agnew, M.A.M. Bourke, W.R. Blumenthal, D.W. Brown, G.C. Kaschner, P. Rangaswamy, The Relation between Texture, Twinning and Mechanical Properties in Hexagonal Aggregates, Materials Science Forum, 408-412 (2002) 263-268. DOI: 10.4028/www.scientific.net/MSF.408-412.263.

[38] M.R. Barnett, A. Sullivan, N. Stanford, N. Ross, A. Beer, Texture selection mechanisms in uniaxially extruded magnesium alloys, Scripta Materialia, 63 (2010) 721-724. DOI: https://doi.org/10.1016/j.scriptamat.2010.01.018.

[39] A. Hanna, H. Azzeddine, Y. Huang, D. Bradai, J.M. Cabrera, T.G. Langdon, An investigation of the thermal stability of an MgDy alloy after processing by high-pressure torsion, Materials Characterization, $151 \quad$ (2019) 519-529. DOI: https://doi.org/10.1016/j.matchar.2019.03.040.

[40] H. Xiao, B. Tang, C. Liu, Y. Gao, S. Yu, S. Jiang, Dynamic precipitation in a Mg-GdY-Zr alloy during hot compression, Materials Science and Engineering: A, 645 (2015) 241 247. DOI: https://doi.org/10.1016/j.msea.2015.08.022. 
[41] H. Azzeddine, D. Bradai, Texture and Microstructure of WE54 Alloy after Hot Rolling and Annealing, Materials Science Forum, 702-703 (2012) 453-456. DOI: 10.4028/www.scientific.net/MSF.702-703.453.

[42] G. Shi, J. Yuan, T. Li, K. Zhang, X. Li, Y. Li, M. Ma, Enhanced precipitation strengthening of extruded Mg-8 wt.\%Al-0.5 wt.\%Zn (AZ80) magnesium alloy by extension twinning, Materials Science and Engineering: A, 774 (2020) 138906. DOI: https://doi.org/10.1016/j.msea.2019.138906.

[43] N. Stanford, M.R. Barnett, Effect of particles on the formation of deformation twins in a magnesium-based alloy, Materials Science and Engineering: A, 516 (2009) 226-234. DOI: https://doi.org/10.1016/j.msea.2009.04.001.

[44] C. Liu, P. Shanthraj, J.D. Robson, M. Diehl, S. Dong, J. Dong, W. Ding, D. Raabe, On the interaction of precipitates and tensile twins in magnesium alloys, Acta Materialia, 178 (2019) 146-162. DOI: https://doi.org/10.1016/j.actamat.2019.07.046.

[45] M. Knezevic, A. Levinson, R. Harris, R.K. Mishra, R.D. Doherty, S.R. Kalidindi, Deformation twinning in AZ31: Influence on strain hardening and texture evolution, Acta Materialia, 58 (2010) 6230-6242. DOI: https://doi.org/10.1016/j.actamat.2010.07.041.

[46] S. Niknejad, S. Esmaeili, N.Y. Zhou, The role of double twinning on transgranular fracture in magnesium AZ61 in a localized stress field, Acta Materialia, 102 (2016) 1-16. DOI: https://doi.org/10.1016/j.actamat.2015.09.026.

[47] O. Sitdikov, R. Kaibyshev, T. Sakai, Dynamic Recrystallization Based on Twinning in Coarse-Grained Mg, Materials Science Forum, 419-422 (2003) 521-526. DOI: 10.4028/www.scientific.net/MSF.419-422.521.

[48] M. Wang, R. Xin, B. Wang, Q. Liu, Effect of initial texture on dynamic recrystallization of AZ31 Mg alloy during hot rolling, Materials Science and Engineering: A, 528 (2011) 2941-2951. DOI: https://doi.org/10.1016/j.msea.2010.11.069.

[49] K.D. Molodov, T. Al-Samman, D.A. Molodov, G. Gottstein, Mechanisms of exceptional ductility of magnesium single crystal during deformation at room temperature: Multiple twinning and dynamic recrystallization, Acta Materialia, 76 (2014) 314-330. DOI: https://doi.org/10.1016/j.actamat.2014.04.066.

[50] J.H. Kim, B.-C. Suh, T.T.T. Trang, J.H. Hwang, N.J. Kim, Orientations of dynamically recrystallized grains nucleated at double twins in $\mathrm{Mg}-4 \mathrm{Zn}-1 \mathrm{Sn}$ alloy, Scripta Materialia, 170 (2019) 11-15. DOI: https://doi.org/10.1016/j.scriptamat.2019.05.029. 
[51] J.-H. Cho, A.D. Rollett, K.H. Oh, Determination of a mean orientation in electron backscatter diffraction measurements, Metallurgical and Materials Transactions A, 36 (2005) 3427-3438. DOI: 10.1007/s11661-005-0016-4.

[52] R. Cottam, J. Robson, G. Lorimer, B. Davis, Dynamic recrystallization of $\mathrm{Mg}$ and $\mathrm{Mg}-\mathrm{Y}$ alloys: Crystallographic texture development, Materials Science and Engineering: A, 485 (2008) 375-382. DOI: https://doi.org/10.1016/j.msea.2007.08.016.

[53] N. Stanford, The effect of rare earth elements on the behaviour of magnesium-based alloys: Part 2 - recrystallisation and texture development, Materials Science and Engineering: A, 565 (2013) 469-475. DOI: https://doi.org/10.1016/j.msea.2012.10.084.

[54] I. Basu, K.G. Pradeep, C. Mießen, L.A. Barrales-Mora, T. Al-Samman, The role of atomic scale segregation in designing highly ductile magnesium alloys, Acta Materialia, 116 (2016) 77-94. DOI: https://doi.org/10.1016/j.actamat.2016.06.024.

[55] S. Sandlöbes, M. Friák, S. Zaefferer, A. Dick, S. Yi, D. Letzig, Z. Pei, L.F. Zhu, J. Neugebauer, D. Raabe, The relation between ductility and stacking fault energies in $\mathrm{Mg}$ and $\mathrm{Mg}-\mathrm{Y}$ alloys, Acta Materialia, 60 (2012) 3011-3021. DOI: https://doi.org/10.1016/j.actamat.2012.02.006.

[56] I. Basu, T. Al-Samman, G. Gottstein, Shear band-related recrystallization and grain growth in two rolled magnesium-rare earth alloys, Materials Science and Engineering: A, 579 (2013) 50-56. DOI: https://doi.org/10.1016/j.msea.2013.04.076.

[57] B. Song, Q. Yang, T. Zhou, L. Chai, N. Guo, T. Liu, S. Guo, R. Xin, Texture control by \{10-12\} twinning to improve the formability of Mg alloys: A review, Journal of Materials $\begin{array}{lllllll}\text { Science } & \& & \text { Technology, } & 35 & \text { (2019) } & \text { 2269-2282. } & \text { DOI: }\end{array}$ https://doi.org/10.1016/j.jmst.2019.03.045.

[58] Y.P. Wu, X.M. Zhang, Y.L. Deng, C.P. Tang, Y.Y. Zhong, Effect of compression conditions on the microstructure and texture of a $\mathrm{Mg}-\mathrm{RE}$ alloy, Materials Science and Engineering: A, 644 (2015) 152-158. DOI: https://doi.org/10.1016/j.msea.2015.07.064.

[59] K. Hantzsche, J. Bohlen, J. Wendt, K.U. Kainer, S.B. Yi, D. Letzig, Effect of rare earth additions on microstructure and texture development of magnesium alloy sheets, Scripta Materialia, 63 (2010) 725-730. DOI: https://doi.org/10.1016/j.scriptamat.2009.12.033.

[60] N. Stanford, M.R. Barnett, The origin of "rare earth" texture development in extruded Mg-based alloys and its effect on tensile ductility, Materials Science and Engineering: A, 496 (2008) 399-408. DOI: https://doi.org/10.1016/j.msea.2008.05.045. 
[61] F.J. Humphreys, M. Hatherly, Chapter 7 - Recrystallization of Single-Phase Alloys, in: F.J. Humphreys, M. Hatherly (Eds.) Recrystallization and Related Annealing Phenomena (Second Edition), Elsevier, Oxford, 2004, pp. 215-IV.

[62] D. Guan, W.M. Rainforth, L. Ma, B. Wynne, J. Gao, Twin recrystallization mechanisms and exceptional contribution to texture evolution during annealing in a magnesium alloy, Acta Materialia, 126 (2017) 132-144. DOI: https://doi.org/10.1016/j.actamat.2016.12.058.

[63] R.A. Vandermeer, B.B. Rath, Microstructural modeling of recrystallization in deformed iron single crystals, Metallurgical Transactions A, 20 (1989) 1933-1942. DOI: 10.1007/BF02650280.

[64] A. Fenghui, L. Bo, Z. Deqin, L. Jinlong, S. Yuhui, Recrystallization Kinetics of Fe-3\%Si after Deformation at High Strain Rate and High Temperature, Materials Research, 22 (2019). [65] Q. Wang, B. Jiang, A. Tang, J. Fu, Z. Jiang, H. Sheng, D. Zhang, G. Huang, F. Pan, Unveiling annealing texture formation and static recrystallization kinetics of hot-rolled $\mathrm{Mg}$ Al-Zn-Mn-Ca alloy, Journal of Materials Science \& Technology, 43 (2020) 104-118. DOI: https://doi.org/10.1016/j.jmst.2020.01.018.

[66] C.W. Su, L. Lu, M.O. Lai, Recrystallization and grain growth of deformed magnesium alloy, Philosophical Magazine, 88 (2008) 181-200. DOI: 10.1080/14786430701805566. 